\title{
Dengue: A Re-Emerging Disease
}

\author{
Batool Sharifi Mood, ${ }^{1, *}$ and Masoud Mardani \\ ${ }^{1}$ Infectious Diseases and Tropical Medicine Research Center, Zahedan University of Medical Sciences, Zahedan, IR Iran \\ ${ }^{2}$ Infectious Diseases and Tropical Medicine Research Center, Shahid Beheshti University of Medical Sciences, Tehran, IR Iran \\ "Corresponding author: Batool Sharifi Mood, Infectious Diseases and Tropical Medicine Research Center, Zahedan University of Medical Sciences, Zahedan, IR Iran. Tel: \\ +98-5413228101-2, Fax: +98-5413236722., E-mail: batoolsharifimood@yahoo.com
}

Received 2015 February 20; Revised 2016 June 08; Accepted 2016 June 13.

\begin{abstract}
Context: Dengue fever(DF) is caused by an arbovirus, which transmitted to humans through the bite of an infected mosquito (Aedes species). Near 2.5 billion people are living in regions where the risk of transmission is high. Until the mid of $20^{\text {th }}$ century, DF was restricted to special parts of tropical and subtropical regions. Dengue hemorrhagic fever(DHF) was first reported in the 1950 s when two epidemics happened in the Philippines and Thailand. Now, with international travels and climate changes, its geographical distribution has been changed and increased.

Evidence Acquisition: We searched medical databases (PubMed and Scopus) from March 1960 to Feb 2015. The key words for the review of literature were as follows: dengue, dengue fever, dengue hemorrhagic fever, epidemiology, transmission routes, clinical manifestation, treatment and prevention of dengue.

Results: Upon the results from literature search, the researchers found that human is the main reservoir for this virus. There are four serotypes of virus. Infection with one serotype cannot protect human against the other three serotypes. Dengue fever begins suddenly with an onset of an influenza-like syndrome and sometimes progresses to severe form of the disease. Treatment is supportive and includes diminishing the fever and balancing fluids and electrolytes. Real-time polymerase chain reaction assays, IgM and IgG-ELISA, and the NS1 ELISA-based antigen assay are available for diagnosis of DHF. There is no FDA-approved vaccine. Mosquito control is the main way for the prevention of dengue.

Conclusions: Dengue virus is not highly contagious and virus cannot be spread directly from person to person. Understanding the epidemiology, clinical manifestation, prompt diagnosis, suitable prevention routes such as mosquito control, and also coordinated effort in the community for disease control are important issues.
\end{abstract}

Keywords: Dengue Fever, Dengue Hemorrhagic Fever, Diagnosis, Prevention, Treatment

\section{Context}

Dengue virus (DV) is an arthropod-borne virus belongs to the family of Flaviviridae, which is transmitted to humans through the bite of an infected Aedes mosquito. There are four serotypes ( 1 to 4 ) of the viruses (1-3). Signs and symptoms of infection begin about 4 - 7 days after the mosquito bite and last between 3 - 10 days. Most of the individuals do not become symptomatic (70\% - 80\%), but some of them $(10 \%-20 \%)$ are symptomatic with clinical presentation like flu syndrome and sometimes the severe forms of disease including dengue hemorrhagic fever (DHF) or dengue shock syndrome (DSS) happen (3-5). In severe form of the disease, there are severe vomiting and uncontrolled hemorrhage in the skin and also blood in urine and stool. There are liver and spleen enlargement. Hepatitis, abdominal pain, hemorrhage, dangerously low blood pressure, and coma are major complications of the disease. Today, dengue is endemic in Asia, Africa, South American countries, and the Caribbean region. About 40\% of the world's population live in countries where the risk of transmission is high. The world health organization
(WHO) estimates that every year about 500,000 cases with DHF (22,000 deaths) occur $(6,7)$. Treatment is supportive and patients should rest and use acetaminophen. Balancing fluids and electrolytes are very important, when DSS is happened. Real-time polymerase chain reaction (RT-PCR) assays, IgM and IgG-ELISA, and the NS1 ELISA-based antigen assay are commercially available for diagnosis of dengue virus $(7,8)$. Until now, there is no approved vaccine to prevent infection. Mosquito control is the main way for the prevention of dengue and for control of epidemic, coordinated inter-organizational efforts are needed $(3,7,8)$. Here, we aimed to review published papers about this disease and study about the epidemiology, clinical manifestation, treatment, and prevention.

\section{Evidence Acquisition}

We searched medical databases including PubMed and Scopus from March 1960 to February 2015. The key words for the review of literature were as follows: dengue, dengue fever, dengue hemorrhagic fever, epidemiology, transmis- 
sion routes, clinical manifestation, treatment and prevention. We found many papers about dengue virus but we selected about 35 articles, which were published recently and showed the main points about the disease. Also, for more understanding of epidemiology, we used older papers.

\section{Results}

In the review of literatures, we found data on epidemiology of dengue, transmission routes, clinical manifestations, and treatment and prevention routes as belows:

\subsection{Epidemiology}

Dengue virus is an arthropod-borne virus, which belongs to the family of Flaviviridae, genus flavivirus (a family which includes other vector-borne viruses such as west Nile virus, Japanese encephalitis virus, and yellow fever virus, which all of them are single-stranded RNA viruses). Dengue fever (DF) occurs when one of the four serotypes of virus infects human $(1,2,6,9)$. Infection with one serotype cannot protect human against the other serotypes. It is important to know involvement with each serotype of virus can put the patient at a greater risk for severe forms of infection like dengue hemorrhagic fever (DHF) and dengue shock syndrome (DSS). Dengue virus is transmitted to human by the mosquito (Aedes aegypti and Aedes albopictus), which are found throughout the world $(4,5,9,10)$. Signs and symptoms of infection begin about $4-7$ days after the mosquito bite and last between 3-10 days. For transmission of the virus by mosquito, it must feed on a body of infected person during a 5-day period when the load of viral is high. This time begins several hours before the patient is symptomatic. Most of people never become symptomatic (70\% - 80\%), but they can infect the mosquitoes and the cycle of transmission is continued (3, 7, 11-13). When an infected mosquito bite the healthy people, the virus needs an incubation period between 8 and12 days in order to mosquito can transmit virus to another person. This mosquito is infected for all of its life (days or a few weeks later) $(3,7,14-16)$. Now, dengue is endemic in at least 100 countries in Asia (more in South-east), Africa, the Americas, and the Caribbean and it is transmitted by Aedes aegypti and Aedes albopictus). However, in the Western Hemisphere, the Aedes aegypti mosquito is the most important vector. Climate changes can have a significant effect on the incidence and prevalence rate of infection. In many of tropical and subtropical countries, dengue is endemic and disease occurs every year, when rainfall is optimal for breeding $(1,4,6,14-16)$. Dengue epidemic happens when a large numbers of mosquitoes feed on the large numbers of people who have no immunity to one of the serotypes. It is said that the four serotypes of virus were originated from monkeys and then transmit to humans in Southeast Asia and some parts of Africa about $100-800$ years ago $(1-3,6,7,15-18)$. Until the second world war, DF was restricted to some countries of the world (Southeastern Asia and Africa), but with beginning of the 2nd world war, transportation of Aedes mosquitoes by cargo could play an important factor for dissemination of the viruses around the world. Today, about 2.5 billion people (near $40 \%$ of the world's population) live in countries where the risk of transmission is high. World health organization estimates that about 50-100 million of world populations become infected yearly, and among them 500,000 DHF with 22,000 deaths (more among young children) are reported (1, 6, 14, 19). Travellers who returning to Europe countries usually get DF from South-east Asia, particularly Thailand and Philippines; however, in the USA dengue found in travelers returning from Mexico and Dominican Republic (20). Autochthonous spread has been reported from the south of France and Croatia, and in 2012 the first European dengue outbreak since the 1920's occurred in Madeira, resulting in over 2,000 cases that among these patients, 120 cases were hospitalized $(15,20)$.

\subsection{Clinical Manifestations}

The spectrum of dengue disease can differ from a mild, nonspecific febrile syndrome to classic DF, and a severe form of the disease, including DHF and DSS $(3,4,7)$. The principal symptoms of dengue fever are high fever, severe headache, severe muscle and bone pain, severe retroorbital pain, joint pain, rash, and sometimes mild bleeding from nose or gums. Fever with other manifestations usually last from 2 to 7 days. When the fever decreases, sometimes other symptoms such as severe abdominal pain, vomiting, and difficulty in breathing develop $(3,7,14)$. These manifestations are due to excessive permeability of the smallest blood vessels, which lead to escaping of fluids from the blood vessels into the peritoneum and pleural cavity. This process can lead to failure of the circulatory system and then lead to shock, and even death, if the balance of fluid and electrolytes is not corrected $(4,5$, 17). Dengue hemorrhagic fever and DSS occur after two or seven days of beginning fever, when the clinical and laboratory warning signs are presented. Patient with DHF has a low platelet count and hemorrhagic tendency (e.g., skin hemorrhages, bleeding nose or gums) $(1,14,17)$. It is reported that younger children and people with their first dengue infection have a milder illness than older children and adults. High-risk groups include pregnant women, children, the elderly, and people with comorbidities such as obesity, diabetes, hypertension, and immunocompromised individuals. These patients should be observed at 
least once daily or admitted to hospital for close observation. Infection with any of the four dengue serotypes can produce the full spectrum of disease and severity. There are three phases of DHF: the febrile phase, the critical phase (plasma leakage), and the convalescent phase $(3,4,7,14,17-$ 23). Sudden increase in the hematocrit ( $\geq 20 \%$ increase from baseline), ascites, pleural effusion, and a low serum albumin level are the evidences of severe forms. Evidence of plasma leak should be monitored for early changes in hemodynamic parameters. Warning signs which usually occur at or after the defervescence phase included sudden change from high to normal or subnormal temperatures, persistent vomiting, abdominal pain, lethargy, pleural effusion, ascites, increases in hematocrit with rapid decrease in platelet count $\left(\leq 100,000\right.$ cells $\left./ \mathrm{mm}^{3}\right)$, bleeding nose or gum, and liver enlargement ( $\geq 2 \mathrm{~cm}$ ). Criteria for severe form include severe plasma leakage, which lead to shock or severe ascites and/or respiratory distress, and severe organ involvement (ALT or AST > 1000, impaired consciousness, and renal or cardiac failure; severe mucosal or cutaneous bleeding). All patients with DHF and DSS recover rapidly with careful monitoring, if they were monitored and managed correctly $(2,5,14,17)$. It is important to know that in the early febrile phase, dengue begins with clinical signs and symptoms similar to malaria and also many of other bacterial diseases (meningococcal infection and leptospirosis) and viral infections (influenza, measles, rubella, and Middle East respiratory syndrome or MERS). A detailed travel history is important, focused on timing and duration of stay in endemic areas, dengue seasonality and epidemic activity in the places visited, and predominant urban or rural stay.

\subsection{Diagnosis}

Dengue infection is characterized by a low titer antibody response in the first infection. IgM antibody is the first immunoglobulin to appear. Then, IgG antibody can be detectable at the end of the first week of disease and then slowly increases. Although, sometimes, high levels of IgG are present even in the acute phase $(3,5,7,24,25)$. In secondary infection, IgG level is promptly and significantly raised and the IgM level increases slowly and even IgM false-negative reactions are observed in this phase. Near $80 \%$ of all dengue cases have a detectable IgM antibody after five days of the beginning of illness, and about 99\% of the patients will show IgM-antibody between day six to ten of illness, which can be detectable for 3 months $(3,7,24)$. Enzyme-linked immunosorbent assay (ELISA) is an important test for the routine dengue diagnosis and has a sensitivity and specificity of approximately $90 \%$ and $98 \%$, respectively. The RT-PCR assay has been developed and this test is commercially available today. The nonstructural protein 1 (NS1) of the dengue viral genome has been shown to be a useful test for the diagnosis of acute dengue infections. The NS1 antigen can be detectable in the serum of the infected patients just one day post onset of symptoms $(3,4,7,26)$. Now, the NS1 ELISA test is commercially available for diagnosis of DV. Other test that helps to find complications such as pleural fluid accumulation and ascites is ultrasound. Echocardiography can assess cardiac function in refractory shock or when myocarditis is suspected. Brady-arrhythmias can be observed and ECG should be performed if the patient is symptomatic.

\subsection{Treatment}

There is no specific treatment for dengue infection and to now, no antiviral therapies have shown benefit $(27,28)$. However, bed rest, diminishing the fever usually by acetaminophen, and a suitable fluid replacement therapy in DSS can be effective, if therapy begins correctly and promptly $(1,3,5)$. Patients with DSS and DHF frequently need to be hospitalized. Patients should use acetaminophen and avoid aspirin and other nonsteroid antiinflammatory drugs, which could worsen bleeding $(3,4,14$, 17). If the disease gets worse in the first 24 hours after the fever, the patient should refer to a hospital immediately to check and monitor for severe forms and complications.

\subsection{Prevention}

Six dengue fever vaccines are in development, and the results of phase III trial were published in July 2014. However, there is no FDA-approved vaccine available yet (3, 4, 29-34). The best way to prevent mosquito bite is elimination of the places where the mosquito lays the eggs, such as artificial containers that hold water for pets and gardening indoor or around the home. Adult mosquitoes usually bite human during the day and at night when the lights are on. Using the repellent on the skin, wearing long sleeves and pants also are other protection tools. Sleeping under a mosquito bed net is another way. If there is someone who is sick in the house, extra precautions are needed to prevent mosquitoes bite $(3,27,31-34)$. Therefore, mosquito control is the best way for the prevention of dengue and when the epidemic form occurs, coordinated efforts in the community are needed to increase the level of people awareness about transmission and prevention routes. The weak points for this study were: 1 - We could not receive article from ISI site; so, we were on scientific sanction. 2- We found many papers about DV, but we study about 35 papers which were newer and could help us for this study. The strength point was collaboration of library staff for searching of useful papers. 


\section{Conclusions}

Dengue virus is not highly contagious and virus cannot be spread directly from person to person. The spectrum of disease is different from a nonspecific febrile syndrome to a classic dengue fever like DHS and DSS. Understanding the epidemiology and clinical manifestation, and prompt diagnosis, and also coordinated efforts in the community for disease control are important issues. Dengue fever is one of the most rapidly emerging infectious diseases in the world, and due to international travel it continues to spread as a travel-related infection. Awareness about dengue fever, its complications, and also management is very important for healthcare staff to decrease mortality and morbidity.

\section{Acknowledgments}

We would like to thank library staff in Boo-Ali hospital located in Zahedan City who helped us in searching the relevant papers.

\section{Footnote}

Authors' Contribution: Each of two authors had an equal role in the design and writing of the manuscript.

\section{References}

1. Guha-Sapir D, Schimmer B. Dengue fever: new paradigms for a changing epidemiology. Emerg Themes Epidemiol. 2005;2(1):1. doi: 10.1186/1742-7622-2-1. [PubMed:15743532].

2. Guzman MG, Halstead SB, Artsob H, Buchy P, Farrar J, Gubler DJ, et al. Dengue: a continuing global threat. Nat Rev Microbiol. 2010;8(12 Suppl):S7-16. doi: 10.1038/nrmicro2460. [PubMed: 21079655].

3. Dengue: Guidelines for Diagnosis, Treatment, Prevention and Control: New Edition. ; 2009.

4. Simmons CP, Farrar JJ, Nguyen v V, Wills B. Dengue. $N$ Engl Med. 2012;366(15):1423-32. doi: 10.1056/NEJMra1110265. [PubMed: 22494122].

5. World Health Organization . Dengue and severe dengue. Media centre; 2013. Available from: http://www.who.int/mediacentre/ factsheets/fs117/en/.

6. Cafferata ML, Bardach A, Rey-Ares L, Alcaraz A, Cormick G. , Gibbons L, et al. Dengue Epidemiology and Burden of Disease in Latin America and the Caribbean: A Systematic Review of the Literature and MetaAnalysis. Value in Health Regional Issues. 2013;2:347-56.

7. Guzman MG, Kouri G. Dengue: an update. Lancet Infect Dis. 2002;2(1):33-42. [PubMed: 11892494].

8. Mitchell-Foster K, Ayala EB, Breilh J, Spiegel J, Wilches AA, Leon TO, et al. Integrating participatory community mobilization processes to improve dengue prevention: an eco-bio-social scaling up of local success in Machala, Ecuador. Trans R Soc Trop Med Hyg. 2015;109(2):126-33. doi: 10.1093/trstmh/tru209. [PubMed: 25604763].

9. de Sa Brito DT, de Siqueira VH, Marteleto MA. [Multiprofessional demand and clientele: influences and challenges for a Master's degree course in educational technology in the health sciences]. Cad Saude Publica. 1999;15 Suppl 2:45-54. [PubMed: 10578077].
10. Helmstetter C, Flossdorf M, Peine M, Kupz A, Zhu J, Hegazy AN, et al Individual $\mathrm{T}$ helper cells have a quantitative cytokine memory. Immunity. 2015;42(1):108-22. doi:10.1016/j.immuni.2014.12.018. [PubMed: 25607461].

11. Moraes GH, de Fatima Duarte E, Duarte EC. Determinants of mortality from severe dengue in Brazil: a population-based case-control study. Am J Trop Med Hyg. 2013;88(4):670-6. doi:10.4269/ajtmh.11-0774. [PubMed: 23400577].

12. Diaz-Quijano FA, Waldman EA. Factors associated with dengue mortality in Latin America and the Caribbean, 1995-2009: an ecological study.Am JTrop Med Hyg. 2012;86(2):328-34. doi: 10.4269/ajtmh.2012.110074. [PubMed: 22302870]

13. Hagenlocher M, Delmelle E, Casas I, Kienberger S. Assessing socioeconomic vulnerability to dengue fever in Cali, Colombia: statistical vs expert-based modeling. Int J Health Geogr. 2013;12:36. doi:10.1186/1476072X-12-36. [PubMed: 23945265].

14. Rigau-Perez JG, Clark GG, Gubler DJ, Reiter P, Sanders EJ, Vorndam AV. Dengue and dengue haemorrhagic fever. Lancet. 1998;352(9132):971-7. [PubMed: 9752834].

15. Hammon WM, Rudnick A, Sather GE. Viruses associated with epidemic hemorrhagic fevers of the Philippines and Thailand. Science. 1960;131(3407):1102-3. [PubMed: 14399343].

16. Nimmannitya S, Halstead SB, Cohen SN, Margiotta MR. Dengue and chikungunya virus infection in man in Thailand, 1962-1964. I. Observations on hospitalized patients with hemorrhagic fever. Am J Trop Med Hyg. 1969;18(6):954-71. [PubMed: 5355242].

17. Halstead SB, Lan NT, Myint TT, Shwe TN, Nisalak A, Kalyanarooj S, et al. Dengue hemorrhagic fever in infants: research opportunities ig nored.Emerg Infect Dis. 2002;8(12):1474-9. doi:10.3201/eid0812.020170. [PubMed: 12498666].

18. Brady OJ, Gething PW, Bhatt S, Messina JP, Brownstein JS, Hoen AG, et al. Refining the global spatial limits of dengue virus transmission by evidence-based consensus. PLoS Negl Trop Dis. 2012;6(8):eee1760. doi: 10.1371/journal.pntd.0001760. [PubMed: 22880140].

19. Bhatt S, Gething PW, Brady OJ, Messina JP, Farlow AW, Moyes $\mathrm{CL}$, et al. The global distribution and burden of dengue. Nature. 2013;496(7446):504-7.doi:10.1038/nature12060. [PubMed: 23563266]

20. Centers for Disease C Prevention. . Travel-associated Dengue surveillance - United States, 2006-2008. MMWR Morb Mortal Wkly Rep. 2010;59(23):715-9. [PubMed: 20559202]

21. Wichmann O, Gascon J, Schunk M, Puente S, Siikamaki H, Gjorup I, et al. Severe dengue virus infection in travelers: risk factors and laboratory indicators. J Infect Dis. 2007;195(8):1089-96. doi: 10.1086/512680. [PubMed: 17357044].

22. Schmidt-Chanasit J, Tenner-Racz K, Poppert D, Emmerich P, Frank $\mathrm{C}$, Dinges $\mathrm{C}$, et al. Fatal dengue hemorrhagic fever imported into Germany. Infection. 2012;40(4):441-3. doi: 10.1007/s15010-011-0208-3. [PubMed: 22002736]

23. Sabchareon A, Sirivichayakul C, Limkittikul K, Chanthavanich P, Suvannadabba S, Jiwariyavej V, et al. Dengue infection in children in Ratchaburi, Thailand: a cohort study. I. Epidemiology of symptomatic acute dengue infection in children, 2006-2009. PLoS Negl Trop Dis. 2012;6(7):ee1732. doi:10.1371/journal.pntd.0001732. [PubMed 22860141].

24. Gasparoni A, Avanzini A, Ravagni Probizer F, Chirico G, Rondini G, Severi F. IgG subclasses compared in maternal and cord serum and breast milk. Arch Dis Child. 1992;67(1 Spec No):41-3. [PubMed: 1536584]

25. Pengsaa K, Yoksan S, Limkittikul K, Wisetsing P, Sirivichayakul C, Hutacharoen $\mathrm{P}$, et al. Maternally transferred neutralising dengue antibodies in Thai infants: a pilot study. Ann Trop Paediatr. 2003;23(3):159-65. doi: 10.1179/027249303322296466. [PubMed 14567830].

26. Halstead SB. Pathogenesis of dengue: challenges to molecular biology. Science. 1988;239(4839):476-81. [PubMed: 3277268]. 
27. Low JG, Sung C, Wijaya L, Wei Y, Rathore APS, Watanabe S, et al. Efficacy and safety of celgosivir in patients with dengue fever (CELADEN): a phase $1 \mathrm{~b}$, randomised, double-blind, placebo-controlled, proof-ofconcept trial. Lancet Infect Dis. 2014;14:706-15.

28. Tam DT, Ngoc TV, Tien NT, Kieu NT, Thuy TT, Thanh LT, et al. Effects of short-course oral corticosteroid therapy in early dengue infection in Vietnamese patients: a randomized, placebo-controlled trial Clin Infect Dis. 2012;55(9):1216-24. doi: 10.1093/cid/cis655. [PubMed: 22865871].

29. WHO . Global strategy for dengue prevention control: 2012-2020 2012. Available from: http://reliefweb.int/sites/reliefweb.int/files/ resources/9789241504034_eng.pdf.

30. WHO . Report of a WHO technical working group meeting on dengue prevention and control Geneva, Switzerland: WHO Headquarters 2012.

31. Sabchareon A, Wallace D, Sirivichayakul C, Limkittikul K, Chanthavanich $P$, Suvannadabba $S$, et al. Protective efficacy of the recombinant, live-attenuated, CYD tetravalent dengue vaccine in Thai schoolchildren: a randomised, controlled phase $2 \mathrm{~b}$ trial. Lancet. 2012;380(9853):1559-67. doi: 10.1016/S0140-6736(12)61428-7. [PubMed: 22975340].

32. Poole-Smith BK, Hemme RR, Delorey M, Felix G, Gonzalez AL, Amador $\mathrm{M}$, et al. Comparison of vector competence of Aedes mediovittatus and Aedes aegypti for dengue virus: implications for dengue control in the Caribbean. PLoS Negl Trop Dis. 2015;9(2):e0003462. doi: 10.1371/journal.pntd.0003462. [PubMed: 25658951].

33. Manrique-Saide P, Che-Mendoza A, Barrera-Perez M, Guillermo-May G, Herrera-Bojorquez J, Dzul-Manzanilla F, et al. Use of insecticidetreated house screens to reduce infestations of dengue virus vectors, Mexico.Emerg Infect Dis. 2015;21(2):308-11. doi: 10.3201/eid2102.140533. [PubMed: 25625483].

34. Brusich M, Grieco J, Penney N, Tisgratog R, Ritthison W, Chareonviriyaphap $\mathrm{T}$, et al. Targeting educational campaigns for prevention of malaria and dengue fever: an assessment in Thailand. Parasit Vectors. 2015;8:43. doi: 10.1186/s13071-015-0653-4. [PubMed: 25612545]. 